ORIGINAL ARTICLE

\title{
Changing patterns of perinatal death, 1982-2000: a retrospective cohort study
}

\author{
R Bell, S V Glinianaia, J Rankin, C Wright, M S Pearce, L Parker
}

Arch Dis Child Fetal Neonatal Ed 2004;89:F531-F536. doi: 10.1136/adc.2003.038414

See end of article for authors' affiliations ......................

Correspondence to: Dr Bell, School of Population and Health Sciences, Faculty of Medical Sciences, University of Newcastle, Newcastle upon Tyne NE2 $4 \mathrm{HH}$, UK;

ruth.bell@ncl.ac.uk

Accepted

24 February 2004

\begin{abstract}
Objective: To describe trends in cause specific stillbirth and neonatal mortality.
Design: Retrospective cohort study.

Setting and participants: 686860 births in 1982-2000, to mothers resident in the Northern Region of England.

Main outcome measures: Cause specific stillbirth and neonatal mortality; rate ratios (RR) and $95 \%$ confidence intervals (Cl) in 1991-2000 compared with 1982-1990.

Results: In singletons, rates of stillbirth and neonatal mortality declined over time (RR stillbirths, 0.81 195\% $\mathrm{Cl} 0.76$ to 0.87$)$; RR neonatal mortality, $0.76(95 \% \mathrm{Cl} 0.70$ to 0.82$))$. Death from congenital anomalies declined substantially for both stillbirths (RR $0.52 ; 95 \% \mathrm{Cl} 0.40$ to 0.68 ) and neonatal mortality (RR 0.58 ; $95 \% \mathrm{Cl} 0.51$ to 0.67$)$. Mortality due to intrapartum hypoxia also fell, by nearly $50 \%$ for stillbirths and $30 \%$ for neonatal deaths. There was no reduction in stillbirths due to antepartum hypoxia in babies weighing $\geqslant 2500 \mathrm{~g}$, or in mortality attributed to infection. In multiples, the risk of death was higher (RR stillbirths, 4.13 (95\% Cl 3.68 to 4.64); RR neonatal death, 7.82 (95\% Cl 7.13 to 8.58)). Stillbirth rates declined significantly (RR $0.71 ; 95 \% \mathrm{Cl} 0.57$ to 0.89 ) but neonatal mortality did not (RR 0.91 ; $95 \% \mathrm{Cl} 0.77$ to 1.08 ). There was no reduction in neonatal mortality resulting from prematurity, or in mortality from congenital anomalies.

Conclusions: There is considerable overlap in the causes of stillbirth and neonatal mortality. Future progress in reducing perinatal mortality requires better understanding of the aetiology of antepartum stillbirth, of the excess risks of prematurity facing multiple births, particularly in the light of their increasing incidence, and of strategies to prevent perinatal infection.
\end{abstract}

$\mathrm{P}$ erinatal mortality has declined over time, but the rate of decline in many industrialised countries has slowed. ${ }^{1}$ Conventionally comprising stillbirths and early neonatal deaths, perinatal mortality has been used as an indicator of health and health care around the time of birth. The definition is now often extended to include all neonatal deaths. $^{2}$ The rationale for grouping these deaths is an assumption that they share similar determinants and strategies for prevention, although recently differences in the aetiologies of stillbirths and neonatal deaths have been highlighted. ${ }^{3}$ Investigation of trends in the underlying causes of perinatal death is necessary to understand the scope for further reductions and to direct future clinical and research effort. This study examines trends in cause specific stillbirth and neonatal death rates over nearly two decades, using data from a population based register with consistent cause of death coding and autopsy in most cases.

\section{METHODS}

\section{Data sources}

Stillbirth and neonatal deaths in 1982-2000 were identified from the Northern Region Perinatal Mortality Survey (PMS). The PMS covers the population resident in the former Northern Region of England; there are currently around 30000 births a year. Notification of cases is made from multiple sources, ensuring high ascertainment, as indicated by annual cross validation with stillbirth and death registrations. ${ }^{4}$ Data for all registered births in the region during the study period were obtained from the Office for National Statistics. Data on cases and live births were merged into a single dataset.

\section{Classification of cause of death}

Cause of death is assigned by a multidisciplinary review team within the local maternity unit and reviewed centrally by the PMS clinical director to ensure consistency of coding. A clinicopathological classification ${ }^{6}$ based on the Wigglesworth classification $^{7}$ is used to code fetal and neonatal factors leading to death. For the purposes of this study, cause of death categories were created by grouping related cause codes (table 1).

\section{Definitions}

- Stillbirths were deaths occurring before birth, at 28 or more completed weeks of gestation.

- Antepartum stillbirths occurred before the onset of labour, and intrapartum stillbirths during labour; the fetus was assumed to be alive at the start of labour unless there was evidence otherwise.

- Neonatal deaths were those occurring within the first 28 days of life.

\section{Analysis}

Stillbirth rates were calculated per 10000 total births (live and still), and neonatal death rates were calculated per 10000 live births. Cause specific death rates were calculated by dividing the number of stillbirths or neonatal deaths in each cause of death category by the appropriate denominator (total or live births). Time trends were analysed by calculating rate ratios (RR), with $95 \%$ confidence intervals (CI), comparing rates in 1991-2000 with those for 1982-1990. The time periods were selected to result in approximately equal 
Table 1 Cause of death classification ${ }^{7}$

\begin{tabular}{ll}
\hline Cause category & Definition \\
\hline Congenital anomalies & $\begin{array}{l}\text { Any genetic or structural defect arising at conception or during embryogenesis } \\
\text { incompatible with life or causing death. }\end{array}$ \\
Death due to hypoxia/anoxia occurring before the onset of labour. All stillborn \\
babies are arbitrarily classified as dying of hypoxia unless death is due to a \\
specific fetal condition or a malformation. This category therefore includes \\
antepartum stillbirths associated with obstetric complications such as \\
antepartum haemorrhage, as well as unexplained antepartum deaths. \\
Includes deaths due to birth trauma occurring during labour or after birth, and \\
unexplained intrapartum stillbirths (not caused by specific fetal conditions or \\
malformation). \\
Death due to conditions associated with prematurity: severe pulmonary \\
immaturity, hyaline membrane disease and intraventricular haemorrhage. \\
and trauma
\end{tabular}$\quad \begin{aligned} & \text { Death due to infection before, during or after delivery. } \\
& \text { Death due to other specific conditions in the fetus: includes isoimmunisation; } \\
& \text { twin-twin transfusion syndrome; idiopathic hydrops fetalis; fetal blood loss, e.g. } \\
& \text { vasa praevia. } \\
& \text { Includes non-intrapartum trauma, unexplained and unexpected neonatal } \\
& \text { deaths, and unclassifiable deaths. }\end{aligned}$

numbers of births in each. To explore whether trends differed in risk factor subgroups, singletons and multiples were analysed separately, and cause specific death rates in different birthweight and maternal age categories were calculated. The analysis was carried out using Stata 6.0.

\section{RESULTS}

There were 3500 stillbirths, 3315 neonatal deaths, and 680045 neonatal survivors during 1982-2000. A total of 15941 births $(2.3 \%)$ resulted from multiple pregnancies, of which 576 were triplet or higher order multiple births. The overall stillbirth rate was 51.0 per 10000 births, 86\% (2994) of which were antepartum deaths. The overall neonatal death rate was 48.5 per 10000 live births. Autopsy was undertaken in $65 \%$ of cases overall; the rate declined from $70 \%$ in 1982 1990 to $59 \%$ in 1991-2000. The autopsy rate was higher in stillbirths $(74 \%)$ than in neonatal deaths $(56 \%)$.

Most stillbirths were attributed to antepartum hypoxia (76\%), with $11 \%$ attributed to intrapartum hypoxia, and $8 \%$ to congenital anomalies. The most common cause of neonatal death was prematurity (39\%), with congenital anomalies accounting for $28 \%$ of deaths and intrapartum hypoxia $13 \%$.

\section{Singleton births: time trends (tables 2 and 3)}

All cause stillbirth and neonatal death rates declined by 2025\% between 1982-1990 and 1991-2000 (table 3). Mortality from congenital anomalies declined by $40-50 \%$ overall. Death resulting from neural tube defects declined dramatically, whereas there was little evidence of reduction in mortality from cardiac anomalies. Death due to chromosome anomalies declined in neonates, but increased fourfold for stillbirths.

Stillbirths due to antepartum hypoxia declined by only $10 \%$ between the two time periods. Death from intrapartum hypoxia or trauma, however, declined substantially, particularly for stillbirths. The rate of stillbirth attributed to infection increased substantially, but this was based on small numbers. There was no reduction in neonatal mortality attributed to infection. Neonatal mortality attributed to prematurity decreased substantially over time.

\section{Singleton births: cause of death by birth weight and maternal age (tables 4 and 5)}

The risk of stillbirth and neonatal death was strongly associated with birth weight; rates increased at lower birth weights, across all cause categories. The stillbirth rate in babies weighing $2500 \mathrm{~g}$ or more showed no significant reduction over time, largely reflecting a lack of change in mortality due to antepartum hypoxia. Neonatal mortality due to intrapartum hypoxia or trauma did not decline for birth weights of $2500 \mathrm{~g}$ or more, in contrast with the stillbirth rate. Neonatal mortality declined in all birthweight categories, and particularly in babies weighing 1500-2499 g.

Table 2 Cause specific death rates (with number of cases in parentheses) for singleton and multiple births, 1982-2000

\begin{tabular}{|c|c|c|c|c|c|c|}
\hline \multirow[b]{2}{*}{ Cause of death } & \multicolumn{3}{|c|}{ Singleton births ( $n=670$ 919) } & \multicolumn{3}{|c|}{ Multiple births ( $n=15$ 941) } \\
\hline & $\begin{array}{l}\text { Antepartum } \\
\text { stillbirth rate }\end{array}$ & $\begin{array}{l}\text { Intrapartum } \\
\text { stillbirth rate }\end{array}$ & $\begin{array}{l}\text { Neonatal } \\
\text { death rate }\end{array}$ & $\begin{array}{l}\text { Antepartum } \\
\text { stillbirth rate }\end{array}$ & $\begin{array}{l}\text { Intrapartum } \\
\text { stillbirth rate }\end{array}$ & $\begin{array}{l}\text { Neonatal death } \\
\text { rate }\end{array}$ \\
\hline Congenital anomalies & $2.5(166)$ & $1.2(80)$ & $13.1(880)$ & $16.3(26)$ & $6.3(10)$ & $35.1(56)$ \\
\hline Neural tube & $0.4(29)$ & $0.6(40)$ & $1.6(108)$ & $5.6(9)$ & $3.8(6)$ & $8.2(13)$ \\
\hline Chromosome & $0.7(50)$ & $0.1(6)$ & $1.8(123)$ & $1.3(2)$ & $0.6(1)$ & $5.6(9)$ \\
\hline Cardiac & $0.3(19)$ & $0(3)$ & $3.4(226)$ & $0.6(1)$ & 0 & $6.3(10)$ \\
\hline Other & $1.0(68)$ & $0.5(31)$ & $6.3(423)$ & $8.8(14)$ & $1.9(3)$ & $15.1(24)$ \\
\hline Antepartum hypoxia & $36.6(2453)$ & $0.1(7)$ & $0.4(28)$ & $126.7(202)$ & 0 & $0.6(1)$ \\
\hline Intrapartum hypoxia & 0 & $5.1(343)$ & $5.7(385)$ & 0 & $15.7(25)$ & $31.4(50)$ \\
\hline Prematurity & 0 & 0 & $14.2(956)$ & 0 & 0 & $202.6(323)$ \\
\hline Infection & $0.4(24)$ & $0.2(12)$ & $4.1(276)$ & $1.3(2)$ & 0 & $22.6(36)$ \\
\hline Miscellaneous & $1.0(69)$ & $0.2(12)$ & $2.7(180)$ & $27.0(43)$ & $3.1(5)$ & $27.6(44)$ \\
\hline Other causes & 0.1 (9) & $0.2(12)$ & 1.4 (97) & 0 & 0 & 1.9 (3) \\
\hline All causes & $40.6(2721)$ & $6.9(466)$ & $44.8(2802)$ & $171.3(273)$ & $25.1(40)$ & $321.8(513)$ \\
\hline
\end{tabular}

Antepartum and intrapartum stillbirth rates were calculated per 10000 total births (live and still); neonatal death rates were calculated per 10000 live births. Antepartum stillbirth was death of a fetus of 28 completed weeks of gestation or more before the onset of labour. Intrapartum stillbirth was death of a fetus of 28 completed weeks of gestation or more, after the onset of labour but before delivery. Neonatal death was death after live birth of a baby, before completion of 28 days of life. 
Table 3 Cause specific death rates (with number of cases in parentheses) in 1982-90 and 1991-2000, and rate ratios, for singleton and multiple births

\begin{tabular}{|c|c|c|c|c|c|c|}
\hline \multirow[b]{2}{*}{ Cause of death } & \multicolumn{2}{|l|}{ Stillbirth rate } & \multirow[b]{2}{*}{ Rate ratio $(95 \% \mathrm{Cl})$} & \multicolumn{2}{|c|}{ Neonatal death rate } & \multirow[b]{2}{*}{ Rate ratio $(95 \% \mathrm{Cl})$} \\
\hline & $1982-90$ & $1991-2000$ & & $1982-90$ & $1991-2000$ & \\
\hline \multicolumn{7}{|c|}{ Singleton births: $(n=670919)$} \\
\hline Congenital anomalies & $4.8(162)$ & $2.5(84)$ & $0.52(0.40$ to 0.68$)$ & $16.6(557)$ & $9.7(323)$ & $0.58(0.51$ to 0.67$)$ \\
\hline Neural tube & $1.9(63)$ & $0.2(6)$ & $0.10(0.04$ to 0.22$)$ & $2.8(94)$ & $0.4(14)$ & 0.15 (0.09 to 0.26$)$ \\
\hline Chromosome & $0.3(10)$ & $1.4(46)$ & $4.63(2.33$ to 9.17$)$ & $2.2(74)$ & $1.5(49)$ & $0.67(0.46$ to 0.95$)$ \\
\hline Cardiac & $0.3(11)$ & $0.3(11)$ & $1.00(0.44$ to 2.32$)$ & $3.8(128)$ & $2.9(98)$ & $0.77(0.59$ to 1.00$)$ \\
\hline Other & $2.3(78)$ & $0.6(21)$ & $0.27(0.17$ to 0.44$)$ & $7.8(261)$ & 4.9 (162) & $0.62(0.51$ to 0.76$)$ \\
\hline Antepartum hypoxia & $39.3(1321)$ & 34.0 (1139) & $0.87(0.80$ to 0.94$)$ & $0.1(4)$ & $0.7(24)$ & $6.02(2.09$ to 17.37$)$ \\
\hline Intrapartum hypoxia & $6.7(226)$ & 3.5 (117) & $0.52(0.42$ to 0.65$)$ & $6.7(225)$ & $4.8(160)$ & $0.71(0.58$ to 0.87$)$ \\
\hline Prematurity & - & - & - & $16.1(538)$ & $12.5(418)$ & $0.78(0.69$ to 0.89$)$ \\
\hline Infection & $0.2(7)$ & $0.9(29)$ & $4.17(1.82$ to 9.51$)$ & $3.9(132)$ & $4.3(144)$ & $1.10(0.87$ to 1.39$)$ \\
\hline Miscellaneous & 1.1 (37) & $1.3(44)$ & $1.20(0.77$ to 1.85$)$ & $2.9(96)$ & $2.5(84)$ & $0.88(0.66$ to 1.18$)$ \\
\hline Other causes & $0.3(10)$ & $0.3(11)$ & $1.11(0.47$ to 2.60$)$ & $1.3(44)$ & $1.6(53)$ & $1.21(0.81$ to 1.80$)$ \\
\hline \multirow{2}{*}{\multicolumn{7}{|c|}{$\begin{array}{l}\text { All causes } \\
\text { Multiple births ( } n=15 \text { 941): }\end{array}$}} \\
\hline & & & & & & \\
\hline Congenital anomalies & $20.9(15)$ & $23.9(21)$ & $1.14(0.59$ to 2.21$)$ & $41.4(29)$ & $31.3(27)$ & $0.75(0.45$ to 1.27$)$ \\
\hline Neural tube & $11.1(8)$ & $8.0(7)$ & $0.71(0.26$ to 1.97$)$ & $10.0(7)$ & $7.0(6)$ & $0.69(0.23$ to 2.07$)$ \\
\hline Chromosome & 0 & 3.4 (3) & - & $7.1(5)$ & $4.6(4)$ & $0.65(0.17$ to 2.41$)$ \\
\hline Cardiac & 0 & 1.1 (1) & - & $8.6(6)$ & $4.6(4)$ & $0.54(0.15$ to 1.91$)$ \\
\hline Other & 9.8 (7) & $11.4(10)$ & $1.17(0.44$ to 3.06$)$ & 15.7 (11) & 15.1 (13) & $0.96(0.43$ to 2.14$)$ \\
\hline Antepartum hypoxia & $155.0(111)$ & $103.7(91)$ & $0.67(0.51$ to 0.88$)$ & $1.4(1)$ & 0 & - \\
\hline Intrapartum hypoxia & 23.7 (17) & $9.1(8)$ & $0.38(0.17$ to 0.89$)$ & $40.0(28)$ & $25.5(22)$ & $0.64(0.36$ to 1.11$)$ \\
\hline Prematurity & - & - & - & 203.0 (142) & $209.7(181)$ & $1.03(0.83$ to 1.28$)$ \\
\hline Infection & $2.8(2)$ & 0 & - & 20.0 (14) & $25.4(22)$ & $1.27(0.65$ to 2.49$)$ \\
\hline Miscellaneous & $30.7(22)$ & $29.6(26)$ & $0.96(0.55$ to 1.70$)$ & $38.6(27)$ & 19.7 (17) & $0.51(0.28$ to 0.94$)$ \\
\hline Other causes & - & - & - & $1.4(1)$ & $2.3(2)$ & - \\
\hline All causes & 233.6 (167) & $166.3(146)$ & $0.71(0.57$ to 0.89$)$ & $346.0(242)$ & $313.9(271)$ & 0.91 (0.77 to 1.08$)$ \\
\hline
\end{tabular}

The overall perinatal mortality was increased for mothers aged 35 or more and for mothers aged less than 20, compared with those aged 20-34 (RR for older mothers, 1.49 (95\% CI 1.33 to 1.66 ) for stillbirths and 1.35 (95\% CI 1.19 to 1.53 ) for neonatal deaths; RR for younger mothers, 1.27 (95\% CI 1.14 to 1.41 ) for stillbirths and 1.40 (95\% CI 1.26 to 1.56$)$ for neonatal deaths).

The association of mortality with age varied by cause of death. Mortality due to intrapartum hypoxia or trauma was not significantly associated with maternal age. The risk of neonatal death due to prematurity was increased in mothers aged under 20 compared with those aged 20-34 (RR 1.91; $95 \%$ CI 1.61 to 2.25$)$. Mothers aged 35 or more had an increase in risk in most cause of death categories, but particularly for stillbirths due to congenital anomalies (RR
1.85; 95\% CI 1.26 to 2.71 ) and antepartum hypoxia (RR 1.46; 95\% CI 1.29 to 1.67). The reduction in the overall stillbirth rate was similar across all age groups (table 5). There was a particularly large decline in the risk of mortality due to congenital anomalies in mothers under 20, whereas in those aged 35 or more there was no significant decline. There was no significant reduction in overall neonatal mortality for mothers under 20, in contrast with older mothers.

\section{Multiple births (tables 2 and 3)}

Multiple births were at significantly higher risk of perinatal death, particularly in the neonatal period. The stillbirth rate was 196.3 per 10000 births compared with 47.5 for singleton births (RR 4.13; 95\% CI 3.68 to 4.64); neonatal death rates were 328.2 and 42.0 per 10000 live births respectively (RR

Table 4 Cause specific death rates (with the number of cases in parentheses) in 1982-90 and 1991-2000, and rate ratios, for singleton births by birth weight

\begin{tabular}{|c|c|c|c|c|c|c|}
\hline \multirow[b]{2}{*}{ Cause of death } & \multicolumn{2}{|l|}{ Stillbirth rate } & \multirow[b]{2}{*}{ Rate ratio $(95 \% \mathrm{Cl})$} & \multicolumn{2}{|c|}{ Neonatal death rate } & \multirow[b]{2}{*}{ Rate ratio $(95 \% \mathrm{Cl})$} \\
\hline & $1982-90$ & $1991-2000$ & & $1982-90$ & $1991-2000$ & \\
\hline \multicolumn{7}{|c|}{ Birth weight $<1500 \mathrm{~g}(\mathrm{n}=6237)$} \\
\hline Congenital anomalies & $216.7(65)$ & $89.6(29)$ & $0.41(0.27$ to 0.64$)$ & $248.8(62)$ & $181.5(52)$ & $0.73(0.51$ to 1.05$)$ \\
\hline Antepartum hypoxia & $1360.0(408)$ & 957.7 (310) & $0.70(0.61$ to 0.81$)$ & $12.0(3)$ & $17.5(5)$ & - \\
\hline Intrapartum hypoxia & $80.0(24)$ & $52.5(17)$ & $0.66(0.35$ to 1.21$)$ & $276.9(69)$ & $90.8(26)$ & $0.33(0.21$ to 0.51$)$ \\
\hline Prematurity & - & - & - & $1894.1(472)$ & $1406.6(403)$ & $0.74(0.66$ to 0.84$)$ \\
\hline All causes & $1693.3(508)$ & $1149.2(372)$ & $0.68(0.60$ to 0.77$)$ & $2744.8(684)$ & $2080.3(596)$ & $0.76(0.69$ to 0.83$)$ \\
\hline \multicolumn{7}{|c|}{ Birthweight $1500-2499 \mathrm{~g}(\mathrm{n}=34$ 835) } \\
\hline Congenital anomalies & $28.2(49)$ & $17.8(31)$ & $0.63(0.40$ to 0.99$)$ & $108.2(182)$ & $52.9(90)$ & $0.49(0.38$ to 0.63$)$ \\
\hline Antepartum hypoxia & 252.5 (439) & $204.6(357)$ & $0.81(0.70$ to 0.93$)$ & 0 & $3.5(6)$ & - \\
\hline Intrapartum hypoxia & $34.5(60)$ & $10.3(18)$ & $0.30(0.18$ to 0.51$)$ & $27.4(46)$ & $15.9(27)$ & $0.58(0.36$ to 0.93$)$ \\
\hline Prematurity & - & - & - & $32.7(55)$ & $7.1(12)$ & $0.21(0.12$ to 0.40$)$ \\
\hline All causes & $326.7(568)$ & $248.7(434)$ & $0.76(0.67$ to 0.86$)$ & 206.4 (347) & $112.8(192)$ & $0.55(0.46$ to 0.65$)$ \\
\hline \multicolumn{7}{|c|}{ Birth weight $\geqslant 2500 \mathrm{~g}(n=626586)$} \\
\hline Congenital anomalies & $1.5(48)$ & $0.8(24)$ & $0.50(0.31$ to 0.82$)$ & $10.0(181)$ & $5.8(181)$ & $0.58(0.49$ to 0.70$)$ \\
\hline Antepartum hypoxia & $15.1(474)$ & $15.1(472)$ & $1.00(0.88$ to 1.14$)$ & $0.03(1)$ & $0.4(13)$ & - \\
\hline Intrapartum hypoxia & $4.5(142)$ & $2.6(82)$ & $0.58(0.44$ to 0.76$)$ & $3.5(110)$ & 3.4 (107) & $0.98(0.75$ to 1.28$)$ \\
\hline Prematurity & - & - & - & $0.4(11)$ & $0.1(3)$ & 0.27 (0.08 to 0.98$)$ \\
\hline All causes & $21.8(687)$ & $19.8(618)$ & $0.91(0.81$ to 1.01$)$ & $18.0(565)$ & $13.4(418)$ & $0.75(0.66$ to 0.85$)$ \\
\hline
\end{tabular}


Table 5 Cause specific death rates (with the numbers of cases in parentheses) in 1982-90 and 1991-2000, and rate ratios, for singleton births by maternal age

\begin{tabular}{|c|c|c|c|c|c|c|}
\hline \multirow[b]{2}{*}{ Cause of death } & \multicolumn{2}{|l|}{ Stillbirth rate } & \multirow[b]{2}{*}{ Rate ratio $(95 \% \mathrm{Cl})$} & \multicolumn{2}{|c|}{ Neonatal death rate } & \multirow[b]{2}{*}{ Rate ratio $(95 \% \mathrm{Cl})$} \\
\hline & $1982-90$ & $1991-2000$ & & $1982-90$ & $1991-2000$ & \\
\hline \multicolumn{7}{|c|}{ Maternal age $<20$ years $(n=71874)$} \\
\hline Congenital anomalies & $8.5(32)$ & $1.5(5)$ & $0.17(0.07$ to 0.44$)$ & $14.5(54)$ & $12.3(42)$ & $0.84(0.56$ to 1.26$)$ \\
\hline Antepartum hypoxia & $48.9(183)$ & 40.1 (138) & $0.82(0.66$ to 1.02$)$ & 0 & $0.9(3)$ & - \\
\hline Intrapartum hypoxia & $5.9(22)$ & $2.0(7)$ & $0.35(0.15$ to 0.81$)$ & $8.1(30)$ & 4.1 (14) & $0.51(0.27$ to 0.96$)$ \\
\hline Prematurity & - & - & - & $26.3(98)$ & $22.2(76)$ & 0.84 (0.62 to 1.14$)$ \\
\hline All causes & $65.1(244)$ & $46.8(161)$ & 0.72 (0.59 to 0.88 ) & 51.1 (175) & $58.3(217)$ & $0.88(0.72$ to 1.07$)$ \\
\hline \multicolumn{7}{|c|}{ Maternal age $20-34$ years $(n=545069)$} \\
\hline Congenital anomalies & $4.1(115)$ & $2.3(63)$ & 0.57 (0.42 to 0.77$)$ & $16.3(452)$ & $9.2(247)$ & $0.57(0.49$ to 0.66$)$ \\
\hline Antepartum hypoxia & $36.6(1022)$ & $32.0(858)$ & $0.87(0.80$ to 0.96$)$ & $0.1(3)$ & $0.6(15)$ & - \\
\hline Intrapartum hypoxia & $6.5(182)$ & $3.6(97)$ & 0.55 (0.43 to 0.71$)$ & $6.5(181)$ & $4.9(130)$ & $0.75(0.60$ to 0.93$)$ \\
\hline Prematurity & - & - & - & $14.2(394)$ & $11.2(300)$ & 0.79 (0.68 to 0.92$)$ \\
\hline All causes & 48.8 (1362) & $40.0(1075)$ & $0.82(0.76$ to 0.89$)$ & 44.4 (1234) & $33.7(900)$ & 0.79 (0.76 to 0.83 ) \\
\hline \multicolumn{7}{|c|}{ Maternal age $\geqslant 35$ years $(n=51$ 189) } \\
\hline Congenital anomalies & $7.6(15)$ & $5.0(16)$ & $0.67(0.33$ to 1.35$)$ & $25.9(51)$ & $10.8(34)$ & $0.42(0.27$ to 0.64$)$ \\
\hline Antepartum hypoxia & $58.5(116)$ & $45.1(143)$ & $0.77(0.60$ to 0.98$)$ & $0.5(1)$ & $1.9(6)$ & - \\
\hline Intrapartum hypoxia & 11.1 (22) & $4.1(13)$ & $0.37(0.19$ to 0.73$)$ & $7.1(14)$ & $5.1(16)$ & 0.71 (0.35 to 1.46$)$ \\
\hline Prematurity & - & - & - & $23.3(46)$ & $13.3(42)$ & $0.57(0.37$ to 0.86$)$ \\
\hline All causes & 78.7 (156) & $58.3(185)$ & 0.74 (0.60 to 0.92$)$ & 71.7 (141) & $41.2(130)$ & $0.57(0.45$ to 0.73$)$ \\
\hline
\end{tabular}

7.82; $95 \%$ CI 7.13 to 8.58 ). The proportion of multiple births that were stillbirths was similar in 1982-1990 and 19912000 , around $9 \%$, whereas the proportion that were neonatal deaths rose from $13 \%$ to $18 \%$.

The risk of death compared with singletons was increased for all cause of death categories. The risk of death due to prematurity was much higher (RR 14.21; 95\% CI 12.55 to 16.11), and these accounted for $39 \%$ of all deaths in multiple births. Deaths from miscellaneous causes, which includes conditions specific to multiple births such as twin-twin transfusion syndrome, were also much more common (RR 14.83 ; $95 \%$ CI 11.70 to 18.80$)$. The smallest increases in risk were observed for congenital anomalies and antepartum hypoxia, with RRs for perinatal mortality of 3.44 (95\% CI 2.78 to 4.25 ) and 3.43 (95\% CI 2.98 to 3.96 ) respectively.

There was no significant reduction over time in neonatal mortality in multiple births, in contrast with singletons (table 3). Further, there was no significant reduction in neonatal mortality due to prematurity. The proportion of low birthweight and very low birthweight babies in multiples increased between 1982-1990 and 1991-2000 (birth weights $<1500 \mathrm{~g}$ increased from $10 \%$ of multiple births to $11.3 \%$; birth weights $1500-2499 \mathrm{~g}$ increased from $43.7 \%$ to $45.4 \%$ : data not shown). Birth weight specific neonatal death rates declined significantly for birth weights $<1500$ g (RR 0.82; $95 \%$ CI 0.70 to 0.96 ) but not for higher birth weights (15002499 g: RR 0.65 (95\% CI 0.39 to 1.10 ); $\geqslant 2500$ g: RR 0.75 (95\% CI 0.36 to 1.58$)$; data not shown).

\section{DISCUSSION}

Over the past two decades, there have been considerable variations in the extent of the decline in stillbirth and neonatal mortality for different causes of death. In singletons, mortality due to congenital anomalies and intrapartum hypoxia reduced substantially. Neonatal mortality due to prematurity, and stillbirths due to antepartum hypoxia also declined, but not in all subgroups. In multiples, the risk of death was increased, and there was no reduction in mortality due to prematurity or congenital anomalies. The proportion of neonatal deaths occurring in multiple births increased substantially.

Although there was overlap in the causes of stillbirths and neonatal deaths (notably congenital anomalies and intrapartum hypoxia), most stillbirths were attributed to antepartum hypoxia, and the largest cause of neonatal death was prematurity. The obstetric antecedents of these deaths may overlap to some extent; for example antepartum haemorrhage, pre-eclampsia and intrauterine growth restriction may all result in stillbirth or preterm delivery.

\section{Methodological issues}

This was a large population based study, using data from one of the most extensive and complete perinatal mortality registers in England. The autopsy rate of $65 \%$ is similar to that reported elsewhere in the United Kingdom, and, in common with other regions, autopsy rates have declined in recent years. ${ }^{8}$ Autopsy may reduce the proportion of unexplained deaths, ${ }^{910}$ and caution should be exercised in interpreting trends in cause specific mortality in the presence of a falling autopsy rate. Over the study period, however, the extent of diagnostic testing is likely to have increased; for example, the proportion of autopsies with histological examination has increased from around $40 \%$ to nearly $100 \%{ }^{4}$

The clinicopathological classification describes fetal and neonatal factors directly leading to death, but does not identify obstetric factors. Most antepartum stillbirths are arbitrarily attributed to antepartum hypoxia. This is a heterogeneous group, including stillbirths associated with recognised obstetric complications, growth restricted fetuses, and genuinely unexplained deaths. Analysis of the obstetric factors contributing to fetal death in this population is described elsewhere. ${ }^{11}$

The study was confined to the examination of mortality within population subgroups for which data were available from national birth statistics. Information on factors such as gestational age, parity, and maternal smoking, which have changed over the study period, remains unavailable nationally. Important changes in obstetric and neonatal practice have also taken place, such as increased screening for congenital anomalies and improvements in neonatal intensive care, but data on the extent and timing of these changes within our population is lacking.

\section{Prematurity}

Deaths attributed to prematurity accounted for $16 \%$ of perinatal deaths in singletons and 39\% in multiples. These deaths declined significantly in singletons but not in multiples. The proportion of multiples born at low birth weight has increased, which may partly account for this observation; however, only very low birth weights showed an improvement 


\section{What is already known}

- Perinatal mortality (stillbirths and neonatal mortality) has declined over the past century

- In recent years, the rate of decline has slowed

- The risk of perinatal mortality is increased for multiple births, low birth weight babies, younger and older mothers

in neonatal mortality. Our findings, although not directly comparable, are consistent with Canadian data showing no recent improvement in twin infant mortality at 32-36 weeks gestation. ${ }^{12}$ Reducing the risk of death due to prematurity in multiple pregnancies remains a significant challenge, particularly in view of the rising incidence of multiple births. ${ }^{13}$

Preterm delivery is reported to be increasing, ${ }^{14}{ }^{15}$ most likely reflecting increased induction and caesarean section rates. ${ }^{16}$ Although dramatic improvements in survival rates for very preterm infants have been reported over recent years, ${ }^{17}$ the risk of neonatal mortality is still strongly associated with low birth weight, ${ }^{18}$ and even small increases in the proportion of babies born at low birth weights have a substantial impact on population neonatal mortality ( S Glinianiaia, unpublished work).

\section{Antepartum hypoxia}

In singletons, stillbirths attributed to antepartum hypoxia showed only a small reduction, confined to birth weights $<2500$ g. Many stillbirths remain unexplained despite autopsy, and there has been limited progress in identifying risk factors. ${ }^{1920}$ A significant proportion are reported to be small for gestational age, ${ }^{21}$ suggesting that better identification of intrauterine growth restriction may have a role in prevention. As unexplained stillbirths account for a substantial and increasing proportion of perinatal deaths, progress in understanding their aetiology is a priority.

Multiple births were at increased risk of stillbirth due to antepartum hypoxia, but the rate decreased significantly over time. This may be a consequence of more intensive monitoring of multiple pregnancies, ${ }^{10}$ although stillbirths averted by elective delivery may simply be deaths deferred. ${ }^{12}$

\section{Intrapartum hypoxia or trauma}

Mortality due to intrapartum hypoxia or trauma declined substantially, during a period when intrapartum management has changed substantially and caesarean section rates have risen. ${ }^{16}$ Although the observed trends are encouraging, caution should be exercised in attributing improvements to specific changes in obstetric practice, and further investigation is needed. Further, the reduction has been greater at low birth weights, whereas neonatal mortality at birth weights $2500 \mathrm{~g}$ or more, the category in which the largest number of deaths occur, has remained largely unchanged. This suggests that there may be further potential to reduce intrapartum related deaths.

\section{Congenital anomalies}

In singletons, deaths due to congenital anomalies declined by nearly half. This may result from increased prenatal diagnosis and termination of pregnancy, ${ }^{22}$ from a reduction in underlying incidence, or from improved survival. Deaths due to neural tube defects showed a dramatic decline, attributable to both increased screening and a reduction in incidence. ${ }^{23} 24$ Neonatal mortality due to chromosome anomalies declined in singletons, but stillbirths increased, perhaps as a result of
What this study adds

- The rate of decline in perinatal mortality shows considerable variation by cause of death

- In singletons, the rate of stillbirth due to antepartum hypoxia remained unchanged for normal birth weight babies over the past two decades

- In multiple births, there has been no improvement in neonatal mortality due to prematurity

- There has been no reduction in mortality attributed to infection

increased cytogenetic testing. Other authors report no decline in mortality from chromosomal anomalies, ${ }^{25}$ attributed to increased incidence resulting from rising maternal age. ${ }^{26}{ }^{27}$ The lack of significant decline in neonatal mortality due to cardiac anomalies in our population is surprising, in view of reported improvements in treatment and survival. ${ }^{28}$

Multiple pregnancies have a higher prevalence of congenital anomalies than singletons, leading to a higher risk of perinatal death. ${ }^{29}$ There was no significant decline in mortality due to congenital anomalies in multiples. This may reflect differences in the sensitivity or uptake of prenatal screening tests and reluctance to opt for selective termination with risks to the healthy twin. ${ }^{30}$

\section{Infection}

In singletons, stillbirths attributed to infection increased significantly, but there were fewer deaths. Neonatal mortality showed no reduction. Awareness of the importance of infection, and in particular group B streptococcal infection, as a cause of perinatal mortality has increased in recent years. ${ }^{31}{ }^{32}$ It is likely that ascertainment has increased over the study period, and the underlying trend is hard to determine. However, infection remains an important and potentially preventable cause of stillbirth and neonatal death.

\section{CONCLUSIONS}

Although some immediate causes of stillbirth and neonatal death differ, there is nevertheless considerable overlap in their determinants. We consider that it remains useful to examine all perinatal deaths together, with rates of stillbirth and neonatal mortality reported separately. In addition, analysis by cause of death is necessary to target future research and clinical effort.

Over the past two decades, stillbirths and neonatal deaths have decreased substantially. Progress has been uneven, however, with considerable variation in the rate of reduction for different causes of death and for some subgroups of births, suggesting scope for further improvement. There has been substantial change in obstetric and neonatal practice and in population risk factors such as maternal age, which have contributed to observed cause specific mortality trends. Further investigation of the aetiology of antepartum stillbirth, the impact of increased elective delivery, and the excess risks facing multiple births is needed to realise the potential for further reductions in perinatal death.

\section{ACKNOWLEDGEMENTS}

We thank Mrs Marjorie Renwick, Operational Manager at the Regional Maternity Surveys Office and the PMS Steering Group for access to the data and are grateful to all the district convenors and coordinators in the Northern Region for their continued collaboration and support of the PMS

We acknowledge the help of staff at the Office for National Statistics for providing birth data for the Northern Region. 


\section{Authors' affiliations}

R Bell, S V Glinianaia, J Rankin, School of Population and Health Sciences, Faculty of Medical Sciences, University of Newcastle, Newcastle upon Tyne NE2 4HH, UK

C Wright, Department of Pathology, Royal Victoria Infirmary, Queen Victoria Road, Newcastle upon Tyne NE1 4LP

M S Pearce, L Parker, School of Clinical Medical Sciences, Faculty of Medical Sciences, University of Newcastle, Sir James Spence Institute, Royal Victoria Infirmary, Queen Victoria Road, Newcastle upon Tyne NE1 4LP

This study was funded by the Newcastle University Hospitals Special Trustees.

\section{REFERENCES}

1 Macfarlane A, Mugford M. Birth counts: statistics of pregnancy and childbirth, Volume 1, text. London: The Stationery Office, 2000

2 Anonymous. Perinatal mortality rates: time for change? Lancet 1991;337:331.

3 Kramer M, Liu S, Lou Z, et al. Analysis of perinatal mortality and its components: time for a change? Am J Epidemiol 2002;156:493-7.

4 Northern RMSO. Annual report 2000. Newcastle: Regional Maternity Survey Office, 2002

5 Hey EN, Welch RG, Lawson JB, et al. Perinatal mortality: a continuing collaborative regional survey. BMJ 1984;288:1717-20.

6 Hey EN, Lloyd DJ, Wigglesworth JS. Classifying perinatal death: fetal and neonatal factors. Br J Obstet Gynaecol 1986;93:1213-23.

7 Wigglesworth J. Monitoring perinatal mortality. A pathophysiological approach. Lancet 1980;2:684-6.

8 CESDI. 8th Annual Report. London: Maternal and Child Health Research Consortium, 2001

9 Cartlidge P, Dawson A, Stewart J, et al. Value and quality of perinatal and infant postmortem examinations: cohort analysis of 400 consecutive deaths. BMJ 1995:310:155-8.

10 Glinianaia S, Pharoah P, Sturgiss S. Comparative trends in causespecific fetal and neonatal mortality in twin and singleton births in the North of England 1982-1994. Br J Obstet Gynaecol 2000;107:452-60.

11 Bell R, Parker L, Macphail S, Wright C. Changes in the cause of late fetal death, 1982-2000. BJOG 2004: in press.

12 Joseph K, Marcoux S, Ohlsson A, et al. Changes in stillbirth and infant mortality associated with increases in preterm birth among twins. Pediatrics 2001;108:1055-61.

13 Glinianaia S, Rankin J, Renwick M. Time trends in twin perinatal mortality in northern England, 1982-94. Twin Res 1998;1:189-95.
14 Ananth C, Misra D, Demissie K, et al. Rates of preterm delivery among black women and white women in the United States over two decades: an ageperiod-cohort analysis. Am J Epidemiol 2001;154:657-65.

15 Joseph K, Kramer M, Marcoux S, et al. Determinants of preterm birth rates in Canada from 1981 through 1983 and from 1992 through 1994. NEngl J Med 1998;339:1434-9.

16 Department of Health. Statistical bulletin. NHS Maternity Statistics, England: 2001-02. London: Department of Health, 2003.

17 Draper E, Manktelow B, Field D, et al. Prediction of survival for preterm births by weight and gestational age: retrospective population based study. BMJ 1999;319:1093-7.

18 Demissie K, Rhoads G, Ananth C, et al. Trends in preterm birth and neonatal mortality among blacks and whites in the United States from 1989 to 1997. Am J Epidemiol 2001;154:307-15.

19 Froen J, Arnestad M, Frey K, et al. Risk factors for sudden intrauterine unexplained death: epidemiologic characteristics of singleton cases in Oslo, Norway, 1986-1995. Am J Obstet Gynecol 2001;184:694-702.

20 Huang D, Usher R, Kramer M, et al. Determinants of unexplained antepartum fetal deaths. Obstet Gynecol 2000;95:215-21.

21 Gardosi J, Mul T, Mongelli M, et al. Analysis of birthweight and gestational age in antepartum stillbirths. Br J Obstet Gynaecol 1998;105:524-30.

22 van der Pal-de Bruin K, Graafmans W, Biermans M, et al. The influence of prenatal screening and termination of pregnancy on perinatal mortality rates. Prenat Diagn 2002;22:966-72

23 Abramsky L, Botting B, Chapple J, et al. Has advice on periconceptional folate supplementation reduced neural-tube defects? Lancet 1999;354:998-9.

24 Rankin J, Glinianaia S, Brown R, et al. The changing prevalence of neural tube defects: a population based study in the North of England, 1984-96. Paediatr Perinat Epidemiol 2000;14:104-10.

25 Neasham D, Dolk H, Vrijheid M, et al. Stillbirth and neonatal mortality due to congenital anomalies: temporal trends and variation by small area deprivation scores in England and Wales, 1986-96. Paediatr Perinat Epidemiol 2001;15:364-73.

26 Morris J, Mutton D, Alberman E. Revised estimates of the maternal age specific live birth prevalence of Down's syndrome. J Med Screen 2002;9:2-6.

27 Hook E. Rates of chromosome abnormalities at different maternal ages. Obstet Gynecol 1981;58:282-5.

28 Wren C, O'Sullivan J. Survival with congenital heart disease and need for follow up in adult life. Heart $2001 ; 85: 438-43$.

29 Mastroiacovo P, Castilla $E$, Arpino C, et al. Congenital malformations in twins: an international study. Am J Med Genet 1999:83:117-24.

30 Edozien L, Mayers F, Gowland M. Difficulties and dilemmas in the management of congenital anomalies in twin pregnancy. Int J Clin Practice 1997;51:305-7.

31 Embleton N. Fetal and neonatal death from maternally acquired infection. Paediatr Perinat Epidemiol 2001;15:54-60.

32 Isaacs D. Prevention of early onset group B streptococcal infection: screen, treat or observe? Arch Dis Child Fetal Neonatal Ed 1998;79:F81-2. 